\title{
Detachable Nanoparticle-Enhanced Chemoimmunotherapy Based on Precise Killing of Tumor Seeds and Normalizing the Growing Soil Strategy
}

Lei Wang,${ }^{\dagger, \dagger}{ }^{\dagger}$ Kaili Ding $^{\dagger}{ }^{\dagger}$ Cuixia Zheng,,${ }^{\dagger}$ Huifang Xiao,${ }^{\dagger}$ Xinxin Liu,${ }^{\dagger}$ Lingling Sun,${ }^{\dagger}$ Rida Omer, ${ }^{\dagger}$ Qianhua Feng, ${ }^{*}, \dagger,+, \S$ Zhenzhong Zhang ${ }^{*} \dagger,+, \S$

${ }^{\dagger}$ School of Pharmaceutical Sciences, Zhengzhou University, 100 Kexue Avenue, Zhengzhou 450001, China

${ }^{\ddagger}$ Collaborative Innovation Center of New Drug Research and Safety Evaluation, Henan Province, Zhengzhou 450001, China

${ }^{\S}$ Key Laboratory of Targeting Therapy and Diagnosis for Critical Diseases, Henan Province, Zhengzhou 450001, China

\section{Materials and Methods}

The Hyaluronic acid (molecular weight: $~ 3.4 \mathrm{KDa}$ ) was purchased from Freda
Biochem
Co.,
Ltd.
(Shandong,
China).

N-(3-Dimethylaminopropyl)-N`-ethylcarbodiimide hydrochloride (EDC) and N-Hydroxysuccinimide (NHS) were purchased from Aladdin Bio-chem Technology Co., Ltd (Shanghai, China). 3-diethylaminopropyl isothiocyanate was purchased from Macklin Bio-chem Technology Co., Ltd. The peptide (Gly-Arg-Val-Gly-Leu-Pro-Gly 98.84\%) was synthesized and analyzed using high-performance liquid chromatography and electrospray ionization mass spectrometry by ChinaPeptides (Shanghai, China). Recombinant Human MMP-2 (rhMMP-2) was purchased from PeproTech.

Anti-CD45-APC-Cy7, anti-CD11b-BB515, anti-CD11c-BV605, anti-F4/80-BV421, anti-Gr-1-PECy7, anti-CD86-APC-R700, abti-CD103-BV510, anti-CD40-PE, anti-CD3-BV510, anti-CD8-PerCP-Cy5, anti-CD4-PE and 
anti-FOXP3-BV421 were all purchased from BioLegend. Antibodies for Calreticulin (CRT) was purchased from Bioss Biotech Co., Ltd (Beijing, China). ELISA kits for IL-10, IL-12, IL-6, IFN- $\gamma$ and TNF- $\alpha$ analysis were purchased from Multi Sciences (Lianke) Biotech Co., Ltd.

\section{Synthesis of HA-grafted DOX prodrug}

Preparation of HA-grafted DOX prodrug according to previous method. ${ }^{1}$ First, HA was dispersed in formamide. Then, a specified amount of $\mathrm{N}$-(3-Dimethylaminopropyl)-N`-ethylcarbodiimide hydrochloride (EDC) and N-hydroxysuccinimide (NHS) were respectively dissolved in formamide, and added them into the above HA solution with the ratio of $\mathrm{COOH}: \mathrm{EDC}: \mathrm{NHS}=1: 5: 5$, followed by stirring this mixture at room temperature for $6 \mathrm{~h}$ for HA activation. Subsequently, $\mathrm{DOX} \cdot \mathrm{HCl}$ was put into above solution, and the mixture was further stirred at room temperature for 24 h. Finally, unreacted free DOX $\bullet H C l$, EDC and NHS were removed by dialysis. The product was obtained by freeze-dried and characterized through ${ }^{1} \mathrm{H}$ NMR (Avane II $500 \mathrm{MHz}$, Bruker, Switzerland) and FT-IR (Thermo Scientific, Nicolet 6700) (Figure S1 and S2, Supporting Information).

\section{Synthesis of MMP-2-DEAP}

The MMP-2 peptide Gly-Arg-Val-Gly-Leu-Pro-Gly $(1 \mathrm{mmol})$ was reacted with DEAP $(10 \mathrm{mmol})$ in DMSO $(10 \mathrm{~mL})$ containing TEA $(1 \mathrm{~mL})$ and pyridine $(0.1 \mathrm{~mL})$ under $35^{\circ} \mathrm{C}$ for $36 \mathrm{~h}$, finally producing MMP-2-DEAP. After the reaction, the resulting solution was dialyzed using a dialysis membrane (Spectra/Por MWCO $3.5 \mathrm{kDa}$; Spectrum Lab., USA) against ${ }^{\circledR}$ fresh water for 2 days. After the end of the dialysis, 
the liquid in the dialysis bag was freeze-dried, and then the chemical structure was confirmed by ${ }^{1} \mathrm{H}$ NMR (Figure S3 and S4).

\section{Synthesis of DOX@HA-MMP-2-DEAP}

Firstly, HA-grafted DOX prodrug was put into $10 \mathrm{~mL}$ of formamide to make it completely dissolved. A specified amount of EDC and NHS were respectively dissolved in formamide, and added them into the above solution, followed by stirring this mixture at room temperature for $6 \mathrm{~h}$, and then ethylenediamine was added into the mixture drop by drop. Next, the solution was reacted at room temperature for $24 \mathrm{~h}$. Subsequently, free reactants were removed through analysis. Finally, the activated prodrug products were obtained after lyophilization.

Secondly, the MMP-2-DEAP was dissolved in formamide, and the EDC and NHS were added into the solution with a certain proportion stirring for $12 \mathrm{~h}$. Next, the prodrug products were added into the solution, followed by reacting $24 \mathrm{~h}$. The resulting solution was purified by dialysis to remove unreacted free reactants.

\section{Evaluation of the p $K_{b}$ for DOX@HA-MMP-2-DEAP}

The $\mathrm{pKb}$ value of DOX@HA-MMP-2-DEAP was obtained by an acid-base titration method. DOX@HA-MMP-2-DEAP was dissolved in deionized water (1 $\mathrm{mg} / \mathrm{mL}$ ) and the $\mathrm{pH}$ was adjusted to 12 with $1 \mathrm{M} \mathrm{NaOH}$. The solution was titrated by the dropwise addition of $0.5 \mathrm{M} \mathrm{HCl}$ solution to obtain the $\mathrm{pH}$ profile. The average $\mathrm{pH}$ value from triplicate titrations was plotted against the volume of added $\mathrm{HCl}$ solution.

\section{Preparation \& Characterization of DOX@HA-MMP-2-DEAP/CXB}

CXB loaded micelles were made by dialysis. ${ }^{2}$ DOX@HA-MMP-2-DEAP was 
put in formamide with CXB at a molar ratio (DOX@HA-MMP-2-DEAP: CXB) of 5:1 stirring to make them mix evenly. Then, the PBS was added to the formamide solution drop by drop until the solution appeared turbid. Dialysis using water and a dialysis bag (MWCO 14,000) was done for $24 \mathrm{~h}$. The solution was finally filtered using a $0.45 \mu \mathrm{m}$ filter to get rid of unloaded CXB.

To investigate tumor acidity and MMP-2-induced switch the morphology and the surface charge of nanoparticle, the nanoparticles were incubated with MMP-2 (1 $\mathrm{ug} / \mathrm{mL}$ ) at $\mathrm{pH}=6.5$ or 7.4 for $4 \mathrm{~h}$, followed by the determination of hydrodynamic diameter and surface charge of the nanoparticles by DLS, transmission electron microscopy (TEM) and zeta-potential measurements, respectively.

The hydrodynamic diameter and the stability of the nanoparticles $(1 \mathrm{mg} / \mathrm{mL})$ in PBS solution ( $\mathrm{pH}$ 7.4) were measured by dynamic light scattering (DLS, Nano-ZS ZEN3600, Malvern). The assembled morphology of DOX@HA-MMP-2-DEAP (1 $\mathrm{mg} / \mathrm{mL})$ was directly observed via TEM $\left({ }^{*} \mathrm{HT} 7700 *\right)$. The loading ratio of and encapsulation efficiency of CXB by DOX@HA-MMP-2-DEAP/CXB nanoparticles were determined by HPLC (Waters, USA) with a ultraviolet-visible detector at 250 $\mathrm{nm}$. They were calculated using following formulas: Loading ratio $=$ (weight of loaded $\mathrm{CXB}) /($ total weight of DOX@HA-MMP-2-DEAP and CXB) $\times 100 \%$; Encapsulation efficiency $=$ (weight of loaded $\mathrm{CXB}) /($ weight of initially added CXB) $\times 100 \%$.

To evaluate the release profile of CXB from the nano-assembly, DOX@HA-MMP-2-DEAP was dissolved in $1 \mathrm{~mL}$ of PBS at different pH in presence 
or absence of rhMMP-2 $(1 \mu \mathrm{g} / \mathrm{mL})$, transferred to a dialysis bag (molecular weight cutoff: $8,000-14,000 \mathrm{Da}$ ), and dialyzed against $9 \mathrm{~mL}$ of PBS solution containing $0.1 \%$ SDS at $37^{\circ} \mathrm{C}$ with stirring at a speed of $100 \mathrm{rpm} / \mathrm{min}$. At different time intervals, the amount of released CXB and DOX in the dialysis buffer was detected by HPLC. The accumulative percentage of CXB and DOX was calculated.

\section{Cell culture}

4T1 cell were cultured in RPMI 1640 medium. All culture medium contained 10\% FBS and 1\% antibiotics (penicillin-streptomycin, 10,000 U/mL), and all cells were incubated at a humidified atmosphere with $5 \% \mathrm{CO}_{2}, 37^{\circ} \mathrm{C}$.

\section{Intracellular uptake of doxorubicin prodrug in vitro using CLSM and flow}

\section{cytometry analysis}

To exploit the receptor-mediated selective intracellular uptake of doxorubicin prodrug in vitro, $4 \mathrm{~T} 1$ cancer cells were seeded into 12 well tissue culture plates $(1 \times$ $10^{5}$ cells/well) and incubated overnight. To validate the HA backbone's role in helping cellular uptake of micelles, 4T1 cells were pre-cultured with free HA prior to the incubation with particles to saturate cellular HA receptors. Results from CLSM (Leica TCS SP8) and flow cytometry analysis (BD Accuri C6) both exhibited a remarkably decreased intracellular fluorescence intensity of HA@DOX, which therefore demonstrated HA-dependent, specific endocytosis.

\section{Evaluation of cytotoxicity}

4T1 cells were seeded into 96 -well plates at a density of $7 \times 10^{3}$ cells each well in the presence of different concentrations of HA, DOX, or HA@DOX. After treatment 
for $24 \mathrm{~h}$ or $48 \mathrm{~h}$, cells were incubated with CCK-8 agent for $1 \mathrm{~h}$ at $37^{\circ} \mathrm{C}$ and the absorbance value (OD) at the wavelength of $450 \mathrm{~nm}$ was measured using a microplate reader (Synergy H1, BioTek).

To study the biocompatibility of blank nanoparticles (HNPs), the cells (HUVEC, 4T1) were seeded into 96 -well plates at a density of $7 \times 10^{3}$ cells each well in the presence of different concentrations of HNPs treatment for $24 \mathrm{~h}$, and then the relative viability of cells was examined by MTT assay as described above.

\section{Induction of immunologic cell death (ICD) with the vesicles}

To determine chemotherapy-induced ICD of the tumor cells, surface expression of calreticulin (CRT) and extracellular release of HMGB1 secretion were examined in vitro. For flow cytometric analysis of cell surface expose of CRT, 4T1 cells were seeded into the 6 -well plate $\left(3 \times 10^{5}\right.$ cells/well $)$ and the next day the cells were incubated with HNPs, DHPD, HPDB or DHPDB for 8 h. DHPDB was pre-incubated with MMP-2 in a buffer of $\mathrm{pH} 6.5$ for $4 \mathrm{~h}$ before added into the cell culture medium. The cells were then harvested, washed twice with PBS, incubated with FITC-conjugated anti-CRT antibody for $30 \mathrm{~min}$. Washing with PBS to remove free antibody before flow cytometric examination.

To detect the release of HMGB1, each group of culture supernatants were collected and the concentration of HMGB1 in the supernatant was measured using an HMGB1 ELISA kit, according to the manufacturer's instructions, respectively.

\section{Preparation of DCs}

In vitro differentiation of DCs was performed with primary bone marrow cells 
from female C57BL/6 mice at 6-8 weeks of age using the induced DCs protocol. ${ }^{3}$ DCs were harvested 6 days after the start of the culture and used for experiments.

\section{In Vitro DC activation with tumor cell supernatant}

$4 \mathrm{~T} 1$ cells were plated at $3 \times 10^{5}$ cells $/ \mathrm{mL}$ in 6 -well plates were cultured in RPMI 1640 medium supplemented with $10 \%$ FCS, $50 \mu \mathrm{M}$ beta-mercaptoethanol and penicillin/streptomycin and incubated with HNPs, DHPD, HPDB, DHPDB. After 24 $\mathrm{h}$, each group-conditioned supernatant was transferred onto the harvested DCs in 12-well plates. Activation of DC was determined after $24 \mathrm{~h}$ using anti-CD86-FITC, anti-CD40-APC antibody or anti-CCR7- Alexa Fluor 488 and then analyzed by flow cytometry.

\section{$\mathrm{PGE}_{2}$ level analysis in vitro}

Briefly, 4T1, RAW264.7 and NIT-3T3 cells were cultured in 96 well-plate overnight. After RAW264.7 and NIT-3T3 cells stimulation with LPS and TGF $\beta$, respectively, the medium was replaced with fresh one. Then, the cells were incubated for $24 \mathrm{~h}$ with $\mathrm{CXB}$ of different concentrations respectively. $4 \mathrm{~T} 1$ cells were incubated with HNPs, DHPD, HPDB, DHPDB for $24 \mathrm{~h}$. The amounts of $\mathrm{PGE}_{2}$ in the supernatants were measured using a $\mathrm{PGE}_{2}$ ELISA Kit (Cayman Chemical) according to the manufacturer's instructions. All samples were conducted in triplicate.

\section{Western blot analysis}

The experimental steps are the same as above. After cells incubated for $24 \mathrm{~h}$, the treated cells were collected to measure the COX-2 protein levels by western blot

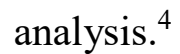




\section{CXCL12 level analysis}

NIT-3T3 cells were seeded in 96 well-plate overnight. After, stimulated by TGF$\beta$ for $24 \mathrm{~h}$, the medium was replaced with fresh one. Then, the cells were incubated with HNPs, DHPD, HPDB, DHPDB for $24 \mathrm{~h}$. The amounts of CXCL12 in the supernatants were measured using a CXCL12 ELISA Kit according to the manufacturer's instructions. All samples were conducted in triplicate.

\section{In Vivo Biodistribution and Pharmacokinetics studies}

The DHPD/IR783 NPs were prepared according to the loading method above. Subsequently, 4T1 tumor-bearing BABL/c mice were i.v. injected with free IR783 and DHPD/IR783, respectively, when the tumor size reached $200 \mathrm{~mm}^{3}$. The fluorescent intensity and the distribution were measured by an IVIS spectrum in vivo imaging system (IVIS, PerkinElmer, USA) at scheduled time points. Moreover, the ex vivo biodistributions of DHPDB and free DOX in tumor and other major organs gave a similar operation step. In addition, following intravenous injections in SD mice and collecting blood samples at various predetermined times, the pharmacokinetic profiles were recorded.

\section{In vivo antitumor activity assay}

The antitumor effect was performed using a 4T1 murine TNBC tumor model. To establish the animal tumor model, $1 \times 10^{6} 4 \mathrm{~T} 1$ cells in $100 \mu \mathrm{L}$ of PBS were subcutaneously injected into the 6-week old mice at the right flank. The tumor-bearing mice were randomly divided into six groups $(n=5)$ when the tumor volume reached $100 \mathrm{~mm}^{3}$. The mice were then treated with PBS, DHPD, HPDB, 
DHDAB or DHPDB at an DOX dose of $5 \mathrm{mg} / \mathrm{kg}$ and CXB dose of $10 \mathrm{mg} / \mathrm{kg}$, respectively for 5 times at an interval of 2 days. The tumor sizes and body weight were monitored every 2 days for 15 days, and the relative tumor volume was calculated as $\mathrm{V}_{t} / \mathrm{V}_{0}\left(\mathrm{~V}_{\mathrm{t}}\right.$ was the tumor volume on $\mathrm{t}$; $\mathrm{V}_{0}$ was the tumor volume on 0$)$. The main organs after treatments harvested for H\&E staining. The tumors from different groups of mice were harvested for H\&E staining and immunofluorescence staining. The $\mathrm{PGE}_{2}$ levels of tumor tissues were examined by ELISA.

\section{Intratumoral infiltration of immune cells}

To study the immune cells, the tumor xenografts were harvested 3 times post treatment and cut into small pieces, immersed in the solution of $1 \mathrm{mg} / \mathrm{mL}$ collagenase IV and $0.2 \mathrm{mg} / \mathrm{mL}$ DNase I for $45 \mathrm{~min}$ at $37^{\circ} \mathrm{C}$. The single cell suspension was stained with fluorescent-labeled antibody according to manufacturer's protocols. To examine the intratumoral infiltration of CD103 DCs $\left(\mathrm{CD} 11 \mathrm{c}^{+} \mathrm{CD} 103^{+}\right)$and the matured DCs $\left(\mathrm{CD} 11 \mathrm{c}^{+} \mathrm{CD} 40^{+} \mathrm{CD} 86^{+}\right)$, cells were stained with anti-CD11c-BV605, anti-CD103-BV510, anti-CD40-PE and anti-CD86-APC-R700 antibodies according to manufacturer's protocols. For the analysis of $\mathrm{CTLs}\left(\mathrm{CD} 3^{+} \mathrm{CD} 4^{-} \mathrm{CD} 8^{+}\right)$, the $\mathrm{T}$ lymphocytes were stained with anti-CD3-BV510, anti-CD4-PE and anti-CD8-PerCP-cy5 antibodies according to manufacturer's protocols. For macrophage analysis, cells were stained with anti-CD11b-BB515, anti-F4/80-BV421 and anti-CD206-AF647. $\mathrm{CD} 11 \mathrm{~b}^{+} \mathrm{F} 4 / 80^{+} \mathrm{CD} 206^{+}$was defined as $\mathrm{M} 2$ phenotype macrophages. To analyze the frequency of $\mathrm{T}$ regs $\left(\mathrm{CD}^{+} \mathrm{CD}^{+} \mathrm{Foxp} 3^{+}\right)$, the lymphocytes were stained with anti-CD3-BV510, anti-CD4-PE, and 
anti-Foxp3-BV421 according to the manufacturer's protocols. The cells were analyzed by flow cytometric measurement (BD FACS Canto ${ }^{\mathrm{TM}}$ ). For the analysis of MDSC $\left(\mathrm{CD} 11 \mathrm{~b}^{+} \mathrm{Gr}-1^{+}\right)$, the cells were stained with anti-CD11b-BB515 and antiGr-1+-PE-cy7 antibodies according to manufacturer's protocols.

\section{Analysis of T cells and DCs in dLNs}

To examine the T lymphocytes and DCs in dLNs, the dLNs were harvested and ground gently to obtain a single cell suspension. Then the single cells were stained with fluorescent-labelled antibody according to the manufacturer's protocols. For the analysis of $\mathrm{CD}^{+} \mathrm{T}$ cells and $\mathrm{CD} 4^{+} \mathrm{T}$ cells, $\mathrm{T}$ lymphocytes in the spleen were stained with anti-CD3-BV510, anti-CD8-PerCP-cy5, anti-CD4-PE according to the manufacturer's protocols. For DCs analysis, cells were stained with anti-CD11c-BV605, anti-CD103-BV510, anti-CD40-PE and anti-CD86-APC-R700 antibodies according to manufacturer's protocols.

\section{Cytokine secretion in the sera}

To examine the levels of IFN- $\gamma$, TNF- $\alpha$, IL-10, IL-12 and IL-6 cytokines in blood, blood from mice treated with different therapeutics was collected and centrifuge to obtain sera. Cytokines in the sera were measured using an ELISA kit according to the manufacturer's instructions.

\section{Investigation of overall survival and lung metastasis}

For $4 \mathrm{~T} 1$ breast metastasis tumor model, $4 \mathrm{~T} 1$ cells $\left(1 \times 10^{6}\right.$ in $\left.100 \mu \mathrm{L}\right)$ were subcutaneously injected into the second right breast of female BALB/c mice $(n=5)$. When the tumor reached to $100 \mathrm{~mm}^{3}$, mice were randomly divided into 6 groups. The 
mice were treated with PBS, HNPs, DHPD, HPDB, DHDAB and DHPDB, respectively. At the 24th d after treatments, the mice were sacrificed. Three lungs of each group were dissected, and metastatic nodules on the surface of lungs were isolated, counted and imaged. To assess the overall survival, tumor-bearing mice were treated as described above $(n=5)$, and monitored.

\section{Statistical Analysis}

Results are given as Mean \pm S.D. One way analysis of variance (ANOVA) was used to determine the significance of the difference. Statistical significance was set at $(* P<0.05, * * P<0.01, * * * P<0.01)$.

\section{Reference}

(1) Gao, N.; Yang, W.; Nie, H.; Gong, Y.; Jing, J.; Gao, L.; Zhang, X., Turn-on theranostic fluorescent nanoprobe by electrostatic self-assembly of carbon dots with doxorubicin for targeted cancer cell imaging, in vivo hyaluronidase analysis, and targeted drug delivery. Biosens Bioelectron 2017, 96, 300-307.

(2) Xiao, H.; Song, H.; Yang, Q.; Cai, H.; Qi, R.; Yan, L.; Liu, S.; Zheng, Y.; Huang, Y.; Liu, T.; Jing, X., A prodrug strategy to deliver cisplatin(IV) and paclitaxel in nanomicelles to improve efficacy and tolerance. Biomaterials 2012, 33 (27), 6507-6519.

(3) Mayer, C. T.; Ghorbani, P.; Nandan, A.; Dudek, M.; Arnold-Schrauf, C.; Hesse, C.; Berod, L.; Stuve, P.; Puttur, F.; Merad, M.; Sparwasser, T., Selective and efficient generation of functional Batf3-dependent $\mathrm{CD} 103^{+}$dendritic cells from mouse bone marrow. Blood 2014, 124 (20), 3081-3091.

(4) Ye, H.; Wang, K.; Wang, M.; Liu, R.; Song, H.; Li, N.; Lu, Q.; Zhang, W.; Du, Y.; Yang, W.; Zhong, L.; Wang, Y.; Yu, B.; Wang, H.; Kan, Q.; Zhang, H.; Wang, Y.; He, Z.; Sun, J., Bioinspired nanoplatelets for chemo-photothermal therapy of breast cancer metastasis inhibition. Biomaterials 2019, 206, 1-12. 
a
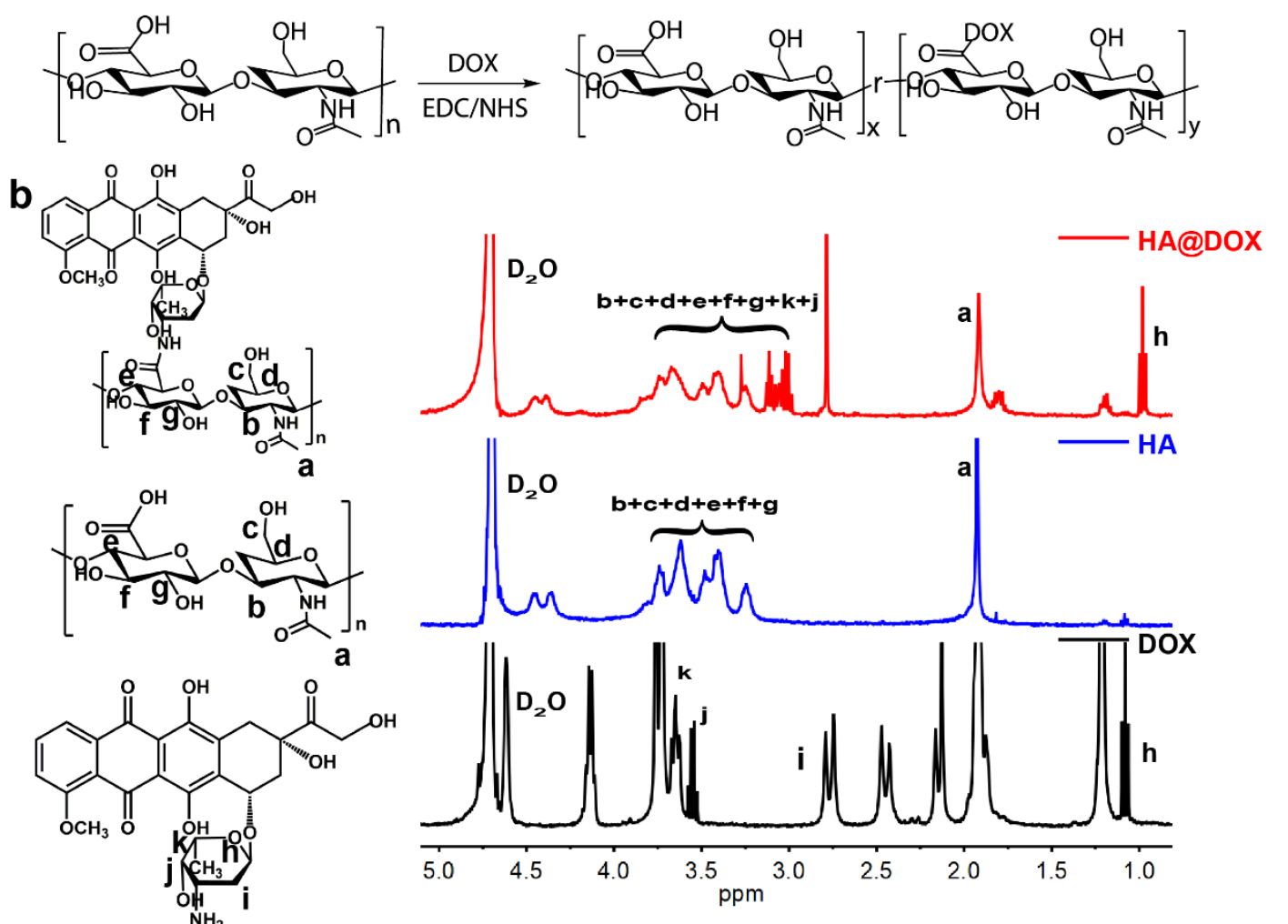

Figure S1. a) The synthetic route of HA@DOX. b) ${ }^{1} \mathrm{H}$ NMR spectrum of DOX, HA and HA@DOX.

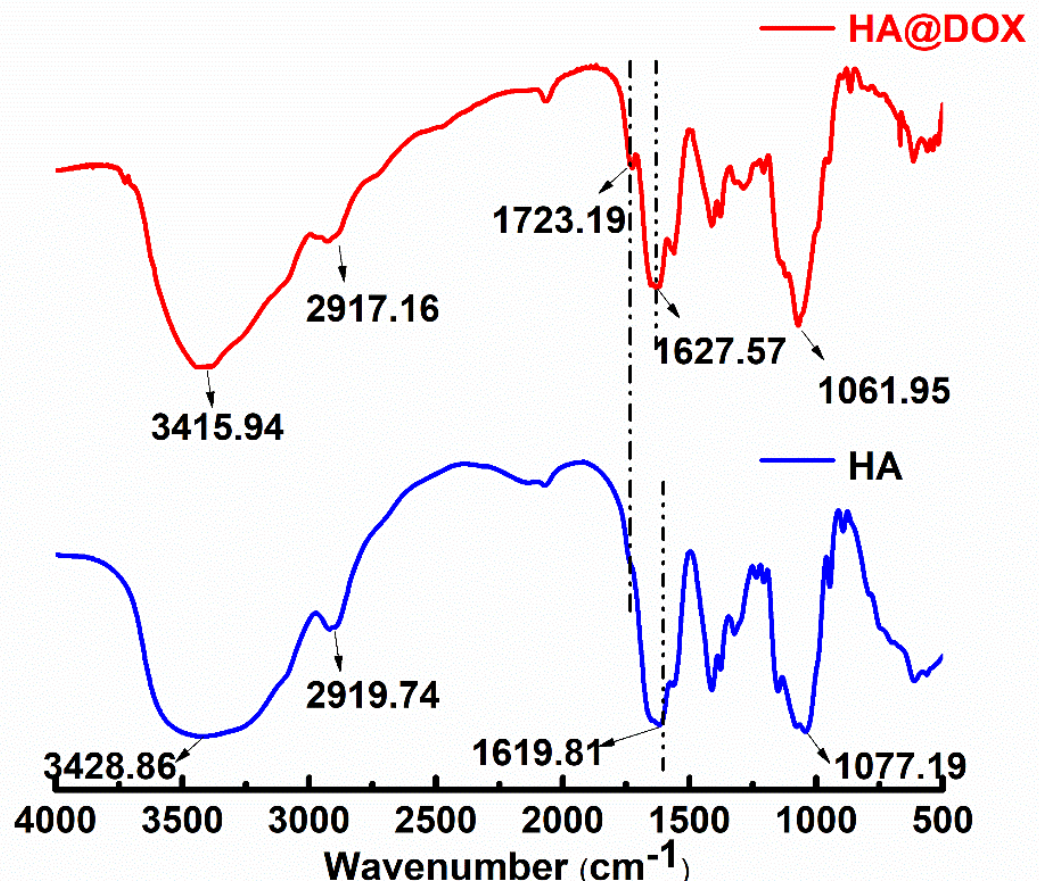

Figure S2. FTIR spectra of HA and HA@DOX. The absorption peak at $1723.19 \mathrm{~cm}^{-1}$ was assigned to the characteristic stretching vibration of the carbonyl group in DOX, indicating that DOX was successfully introduced to HA. 
<smiles>CCN(CC)CCCN=C=C=S</smiles><smiles>CCN(CC)CCCNC(=S)NCC(=O)NC(CCCNC(=N)N)C(=O)NC(C(=O)NCC(=O)NC(CC(C)C)C(=O)N1CCCC1C(=O)NCC(=O)O)C(C)C</smiles>

Figure S3. The synthetic of MMP-2-DEAP.<smiles>CC(NC(=S)NCCCN1CCCCC1)C(=O)NC(CCCNC(=N)N)C(=O)NC(C(=O)NCC(=O)NC(CC1CC1)C(=O)N1CCCC1C(=O)NCC(=O)O)(C1CC1)C1CC1</smiles>

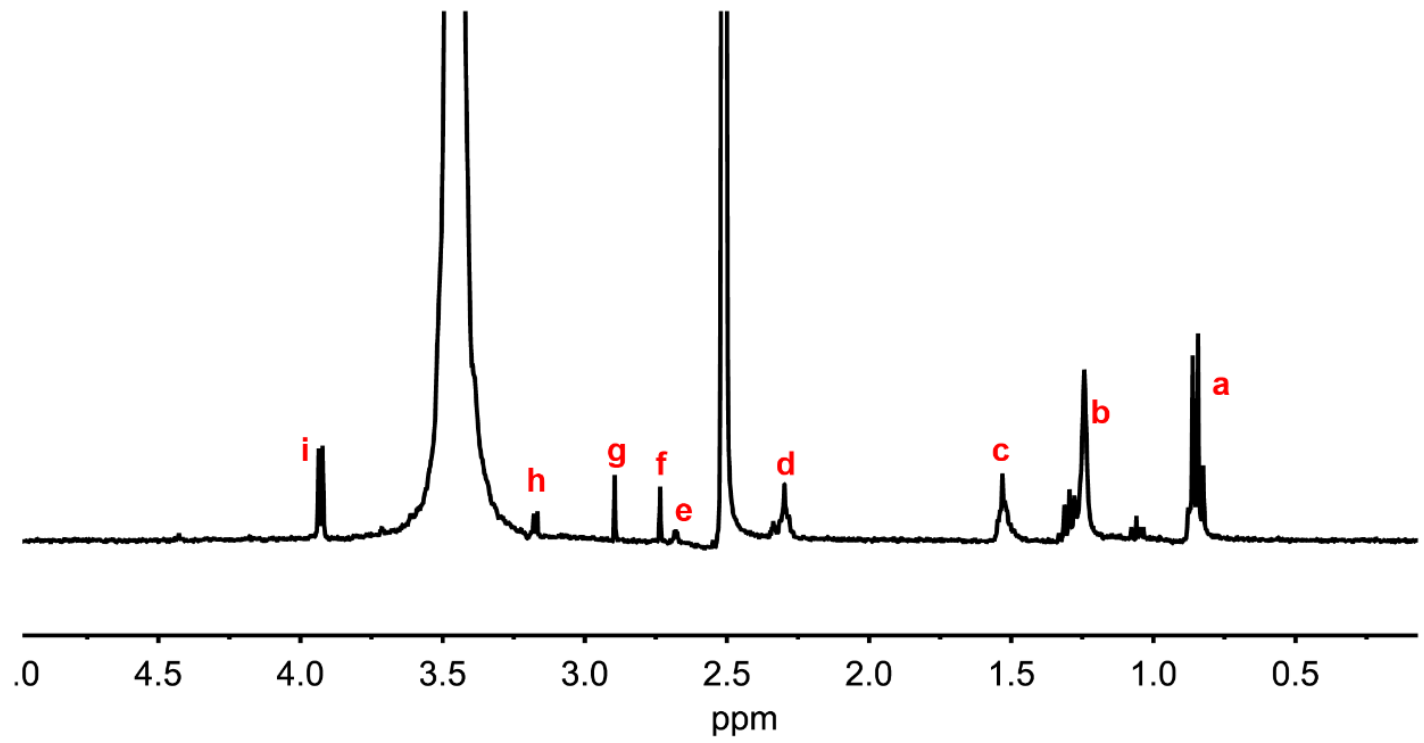

Figure S4. The ${ }^{1} \mathrm{H}-\mathrm{NMR}$ spectrum of MMP-2-DEAP. 


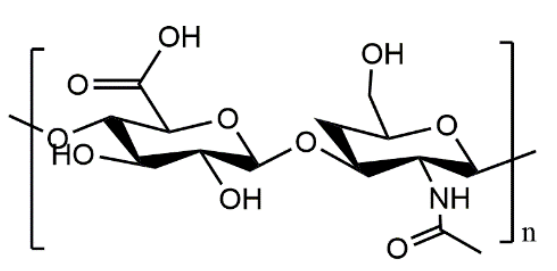

HA

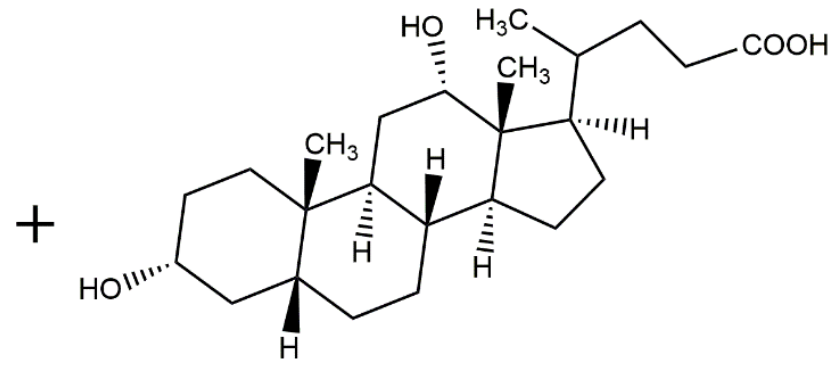

DOCA
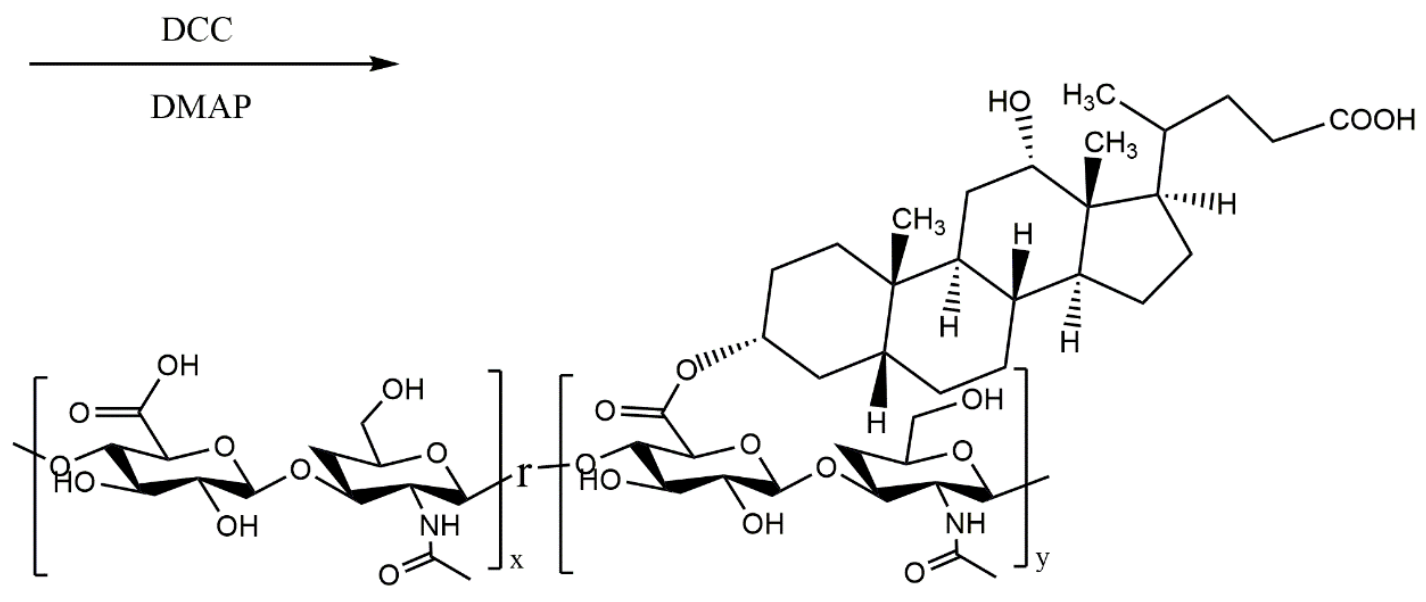

HA-DOCA

Figure S5. The synthetic of HA-DOCA. 

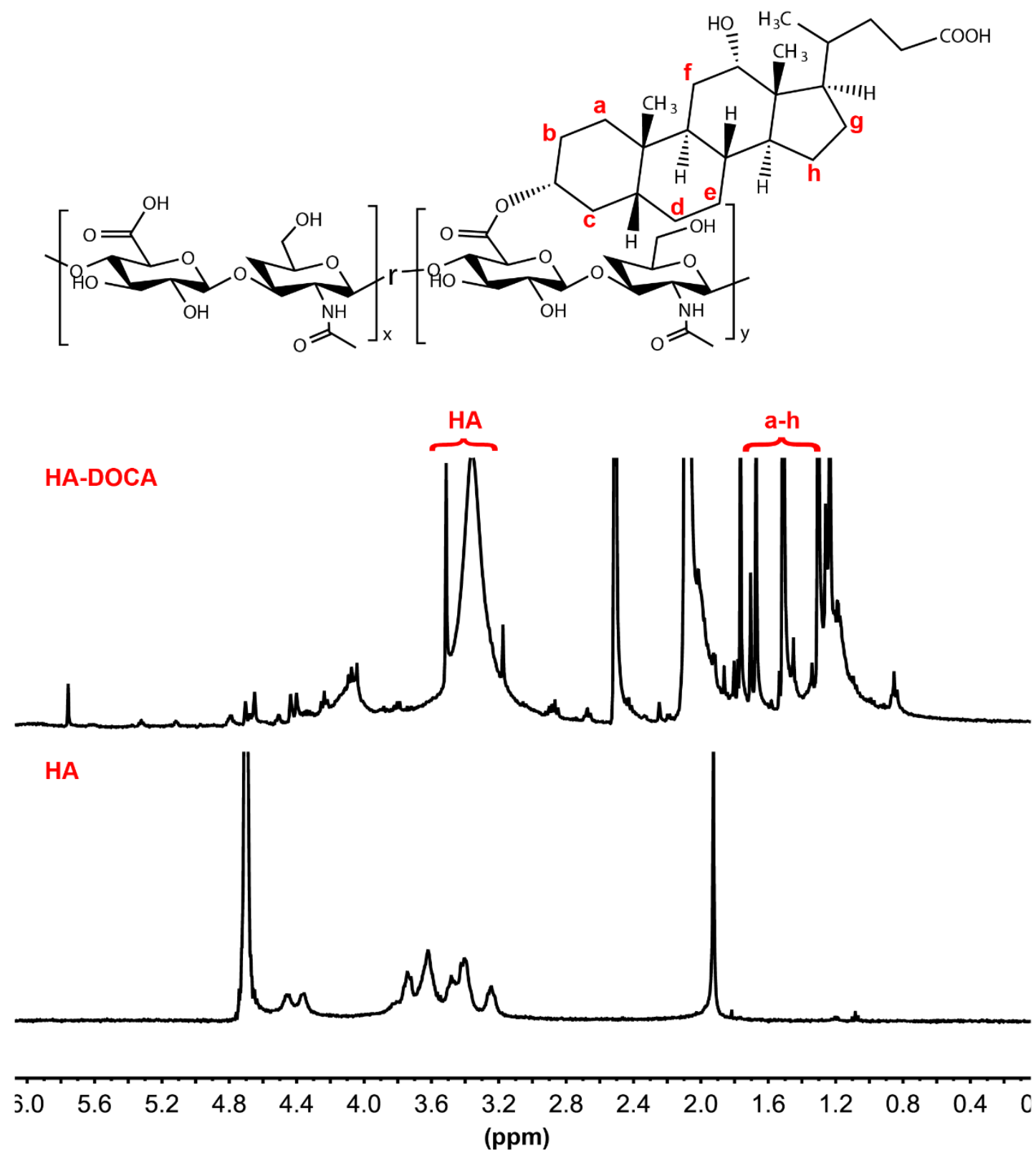

Figure S6. ${ }^{1} \mathrm{H}$ NMR spectrum of HA-DOCA and HA. 

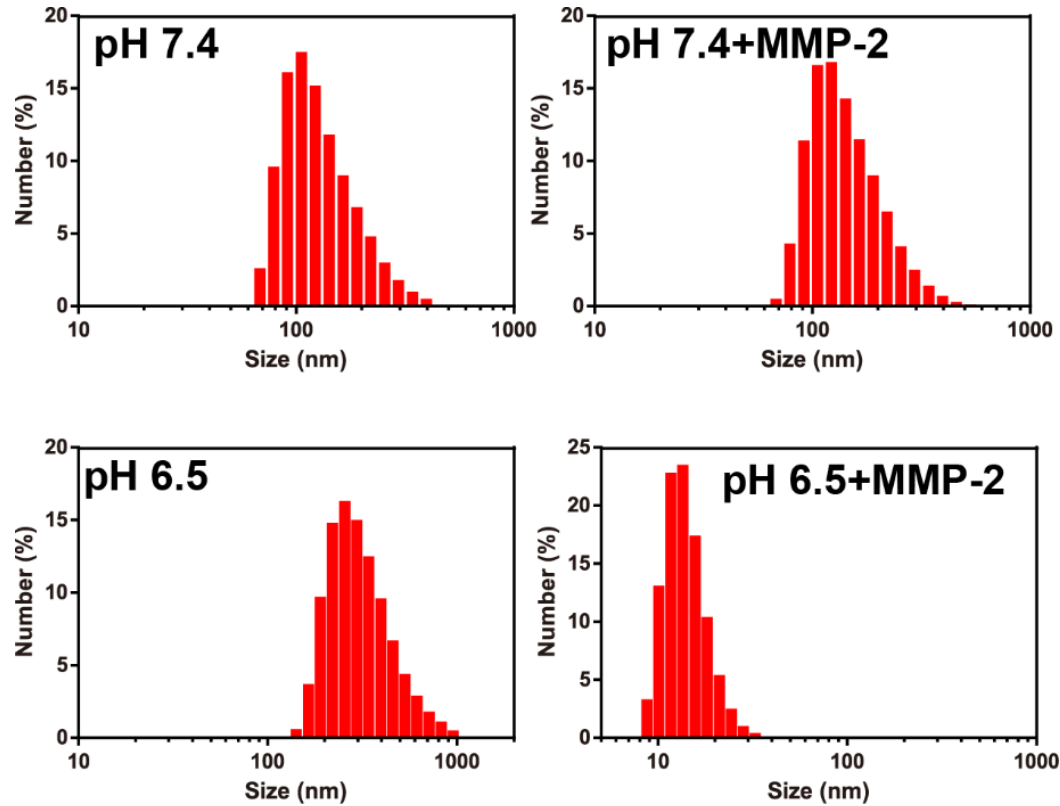

Figure S7. The hydrodynamic size of DHPD nanoparticles at different conditions

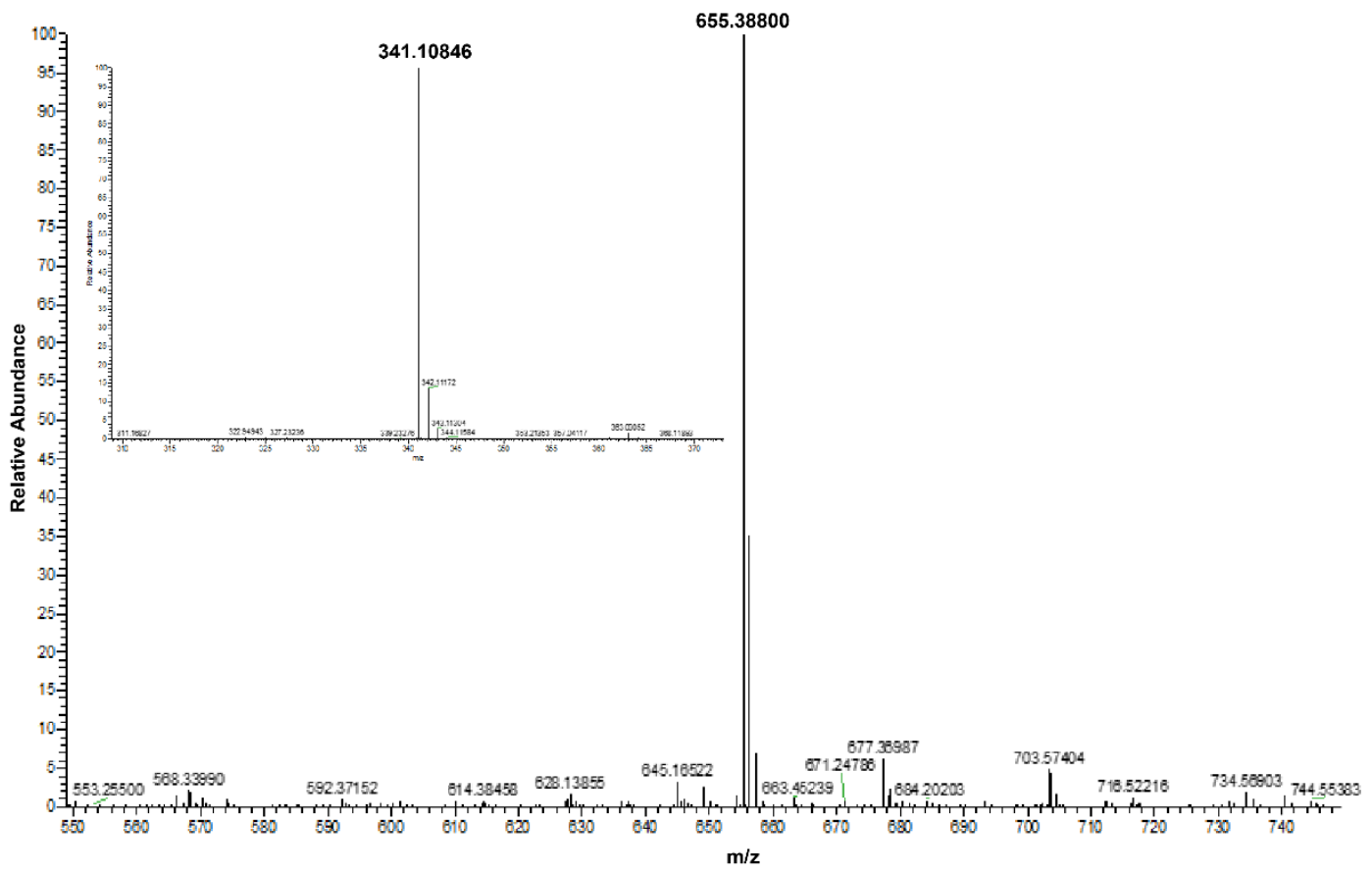

Figure S8. ESI-MS spectrum of GPLGVRG after incubation in a buffer solution of MMP-2. 
a

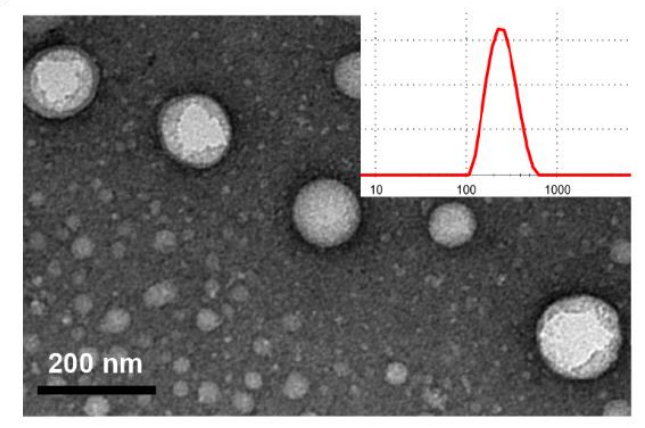

b

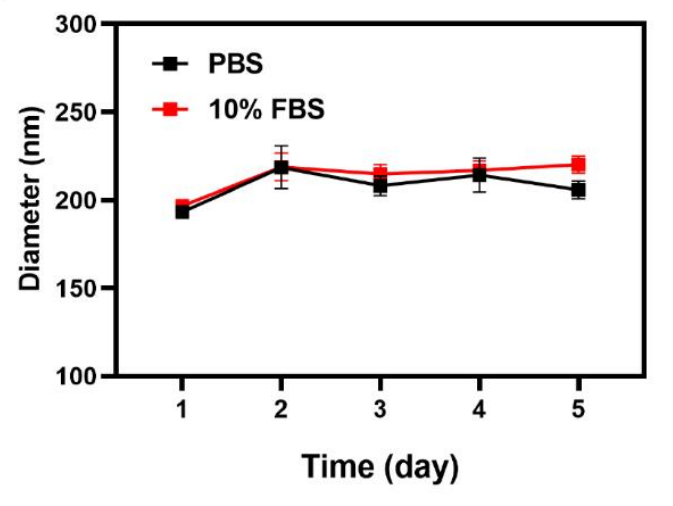

Figure S9. a) TEM images and the hydrodynamic size of DHPDB nanoparticles; b) The stability of nanoparticles in PBS or 10\%FBS.

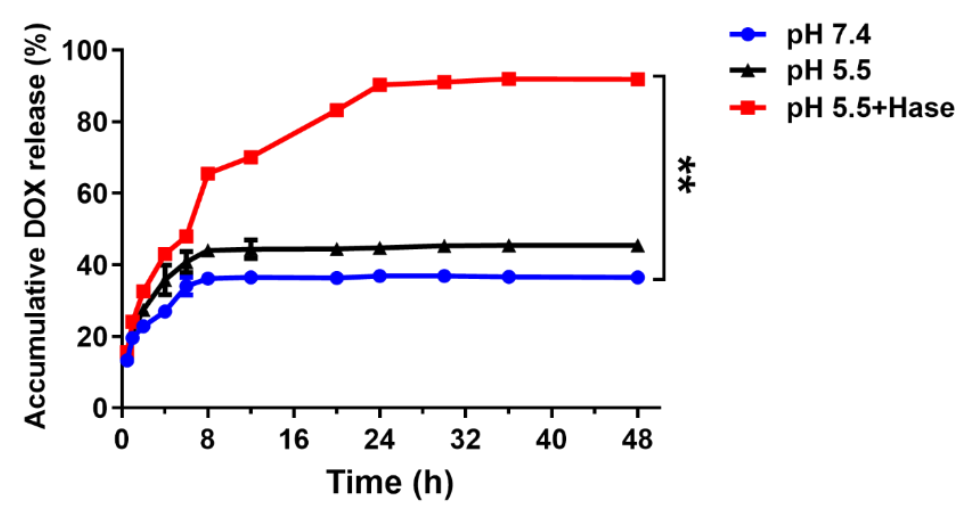

Figure S10. DOX release profiles of HA@DOX at different conditions $\left({ }^{*} P<0.05 ;{ }^{* *} P<\right.$ $0.01)$.

a

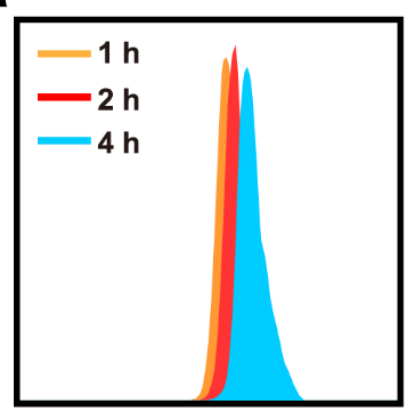

b

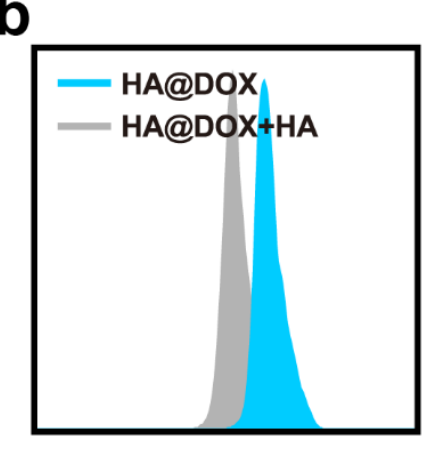

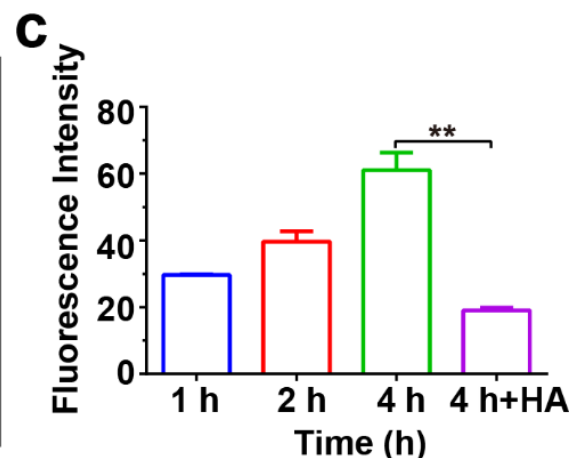

Figure S11. a) The cellular uptake of HA@DOX in 4T1 cells was measured by flow cytometry. b) Cellular uptake in 4T1 cells with or without preincubation with $10 \mathrm{mg} / \mathrm{mL} \mathrm{HA}$ by flow cytometry. c) The fluorescence intensity of the cellular uptake of HA@DOX in CLSM observation $(* P<0.05 ; * * P<0.01)$. 
a

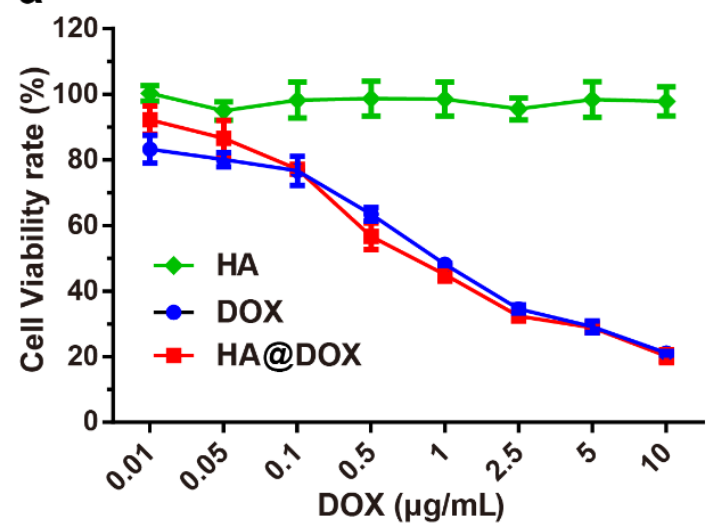

b

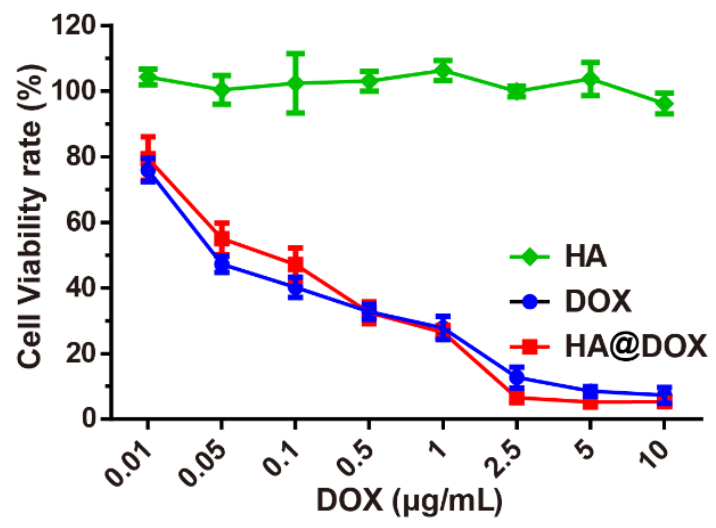

Figure S12. a) and b) The cell viability of free DOX and HA@DOX at $24 \mathrm{~h}$ and $48 \mathrm{~h}$ respectively.

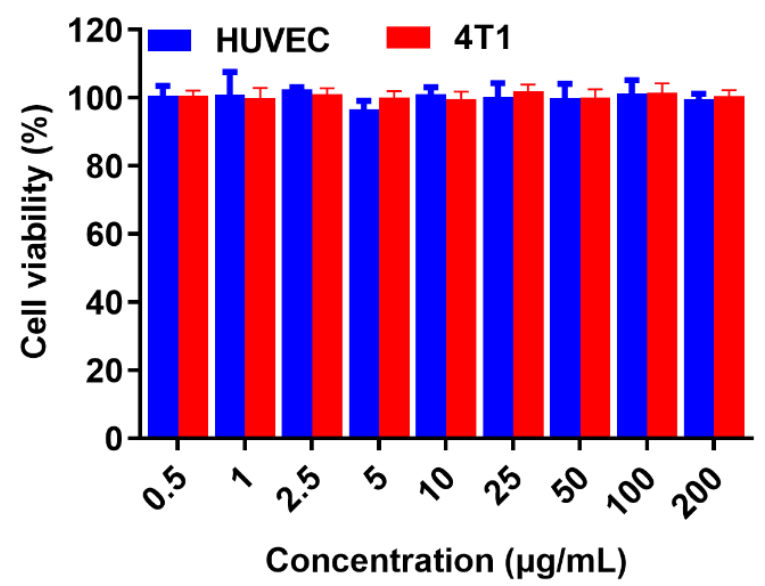

Figure S13. The cytotoxicity of blank nanoparticles in HUVEC and 4T1 cells

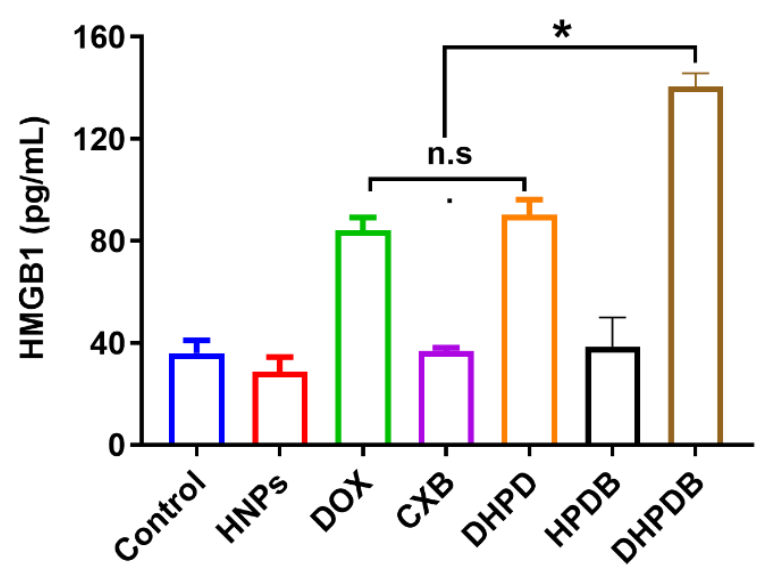

Figure S14. The released HMGB1 of $4 \mathrm{~T} 1$ tumor cells $\left({ }^{*} P<0.05 ; * * P<0.01\right)$. 

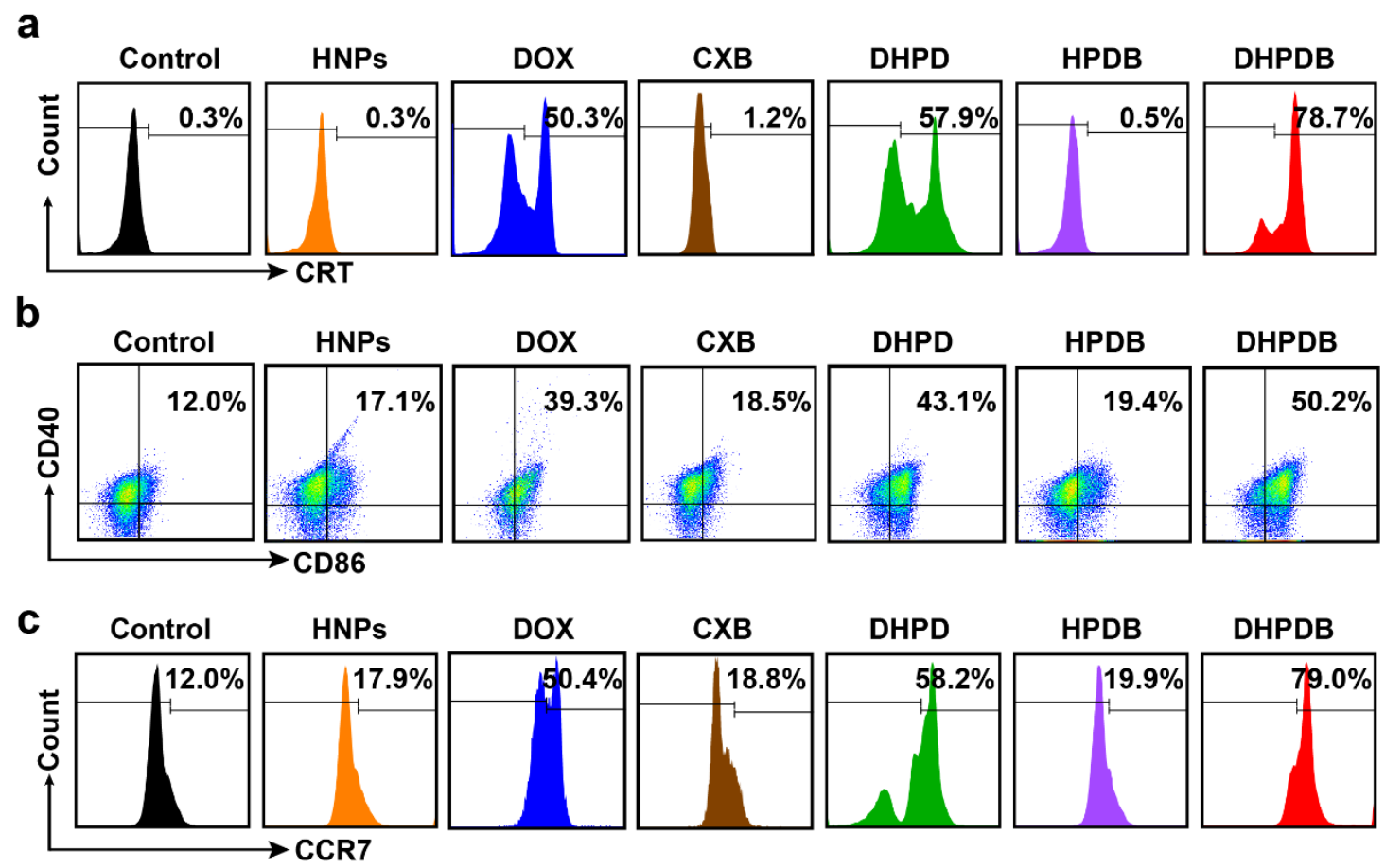

Figure S15. a) FCM examination of CRT exposure on the surface of 4T1 cells. b) and c) FCM measurement of DC maturation and CCR7 expression.

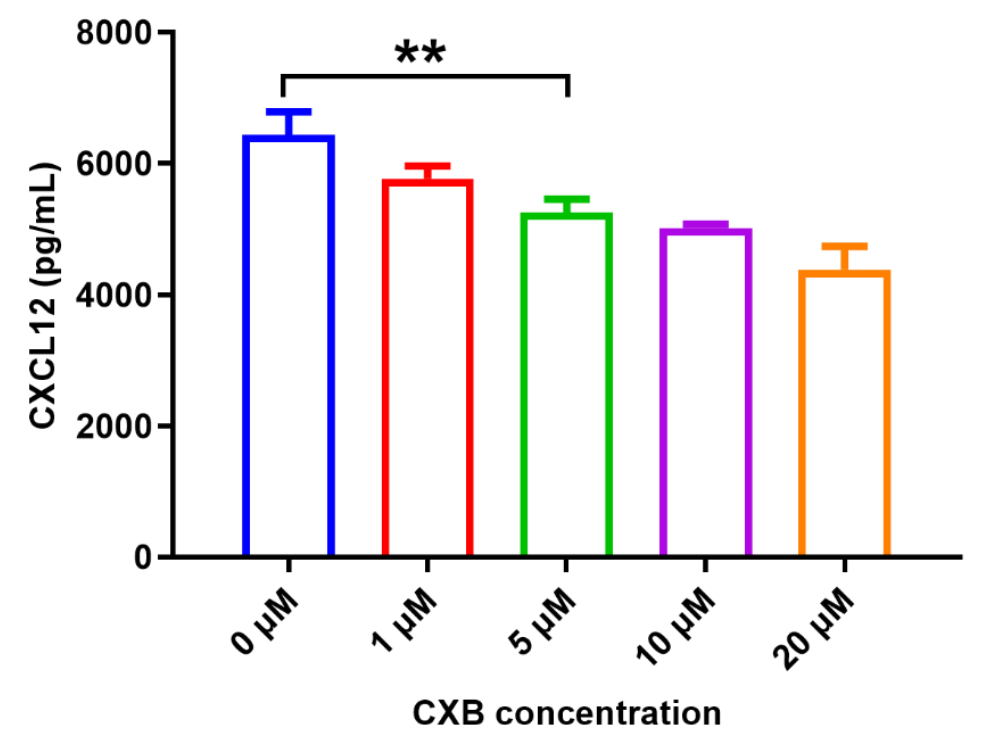

Figure S16. CXCL12 released from TGF- $\beta$-stimulated fibroblasts after being treated with CXB for $24 \mathrm{~h}(* P<0.05 ; * * P<0.01)$. 
a

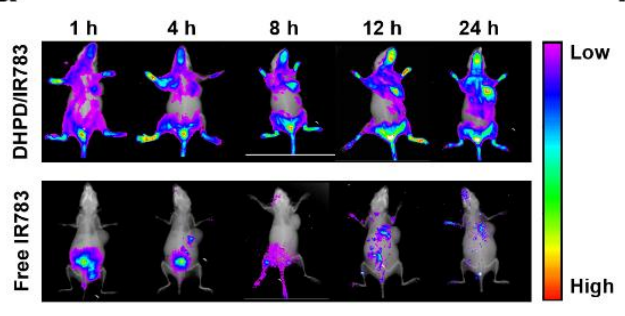

b

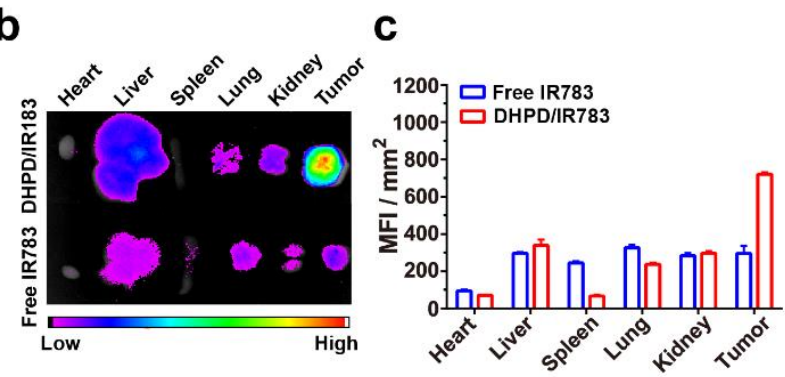

Figure S17. Tumor targeting in vivo. a) In vivo fluorescence imaging of the 4T1-bearing BABL/C mice after intravenous injection with free IR783 and DHPD/IR783 NPs at different time points. b) Ex vivo fluorescence images of important tissues collected from the mice $24 \mathrm{~h}$ after administration and c) fluorescence intensity of the IR783 signal.

a

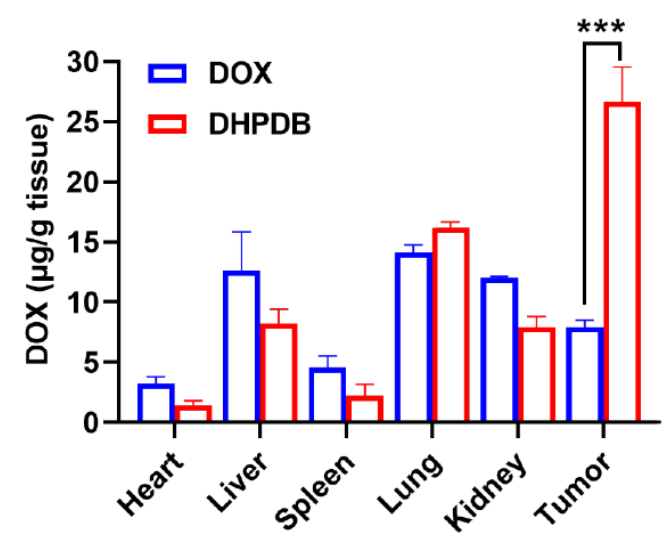

b

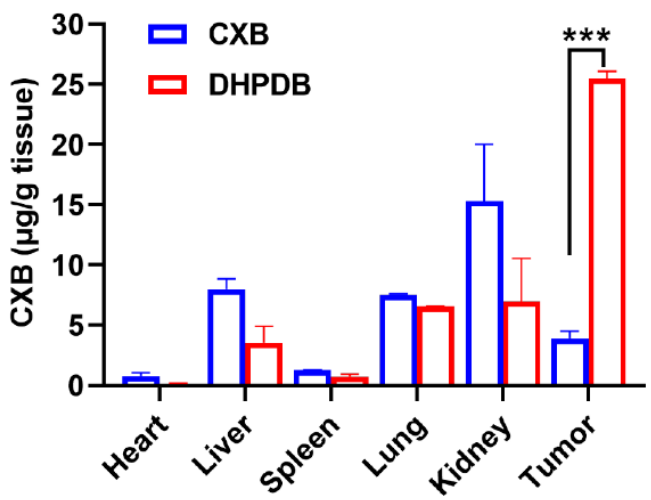

Figure S18. Biodistribution of DOX measured at $24 \mathrm{~h}$ post intravenous injection of free DOX and DHPDB by measuring the concentrations of DOX with HPLC $\left({ }^{*} P<0.05 ;{ }^{* *} P<0.01\right.$; *** $P<0.001)$.

a

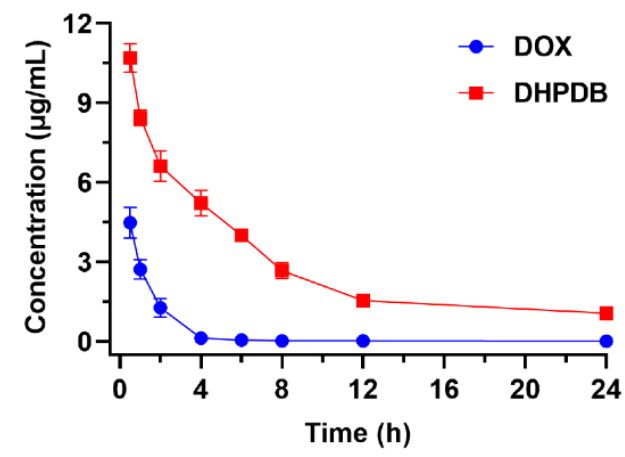

b

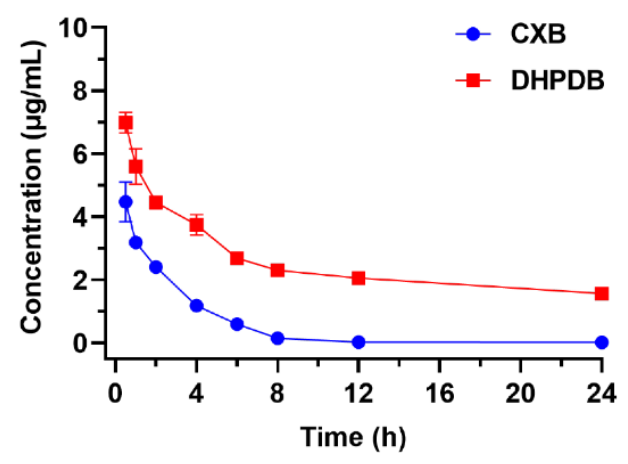

Figure S19 Representative plasma concentration-time profiles of free DOX, free CXB and DHPDB after i.v. injection into rats. 


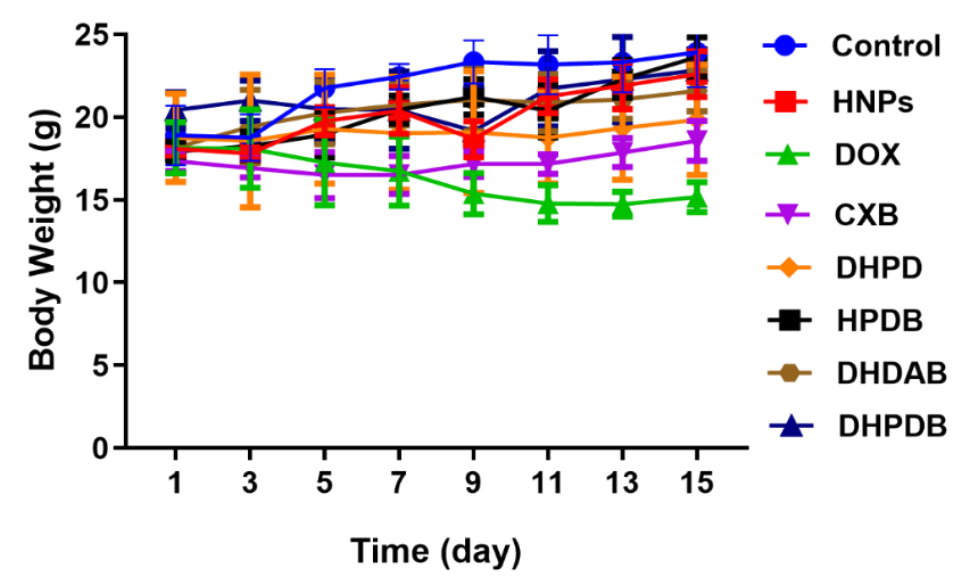

Figure S20. Body weight change of the 4T1-bearing BABL/c mice monitored during the anti-tumor therapy period.

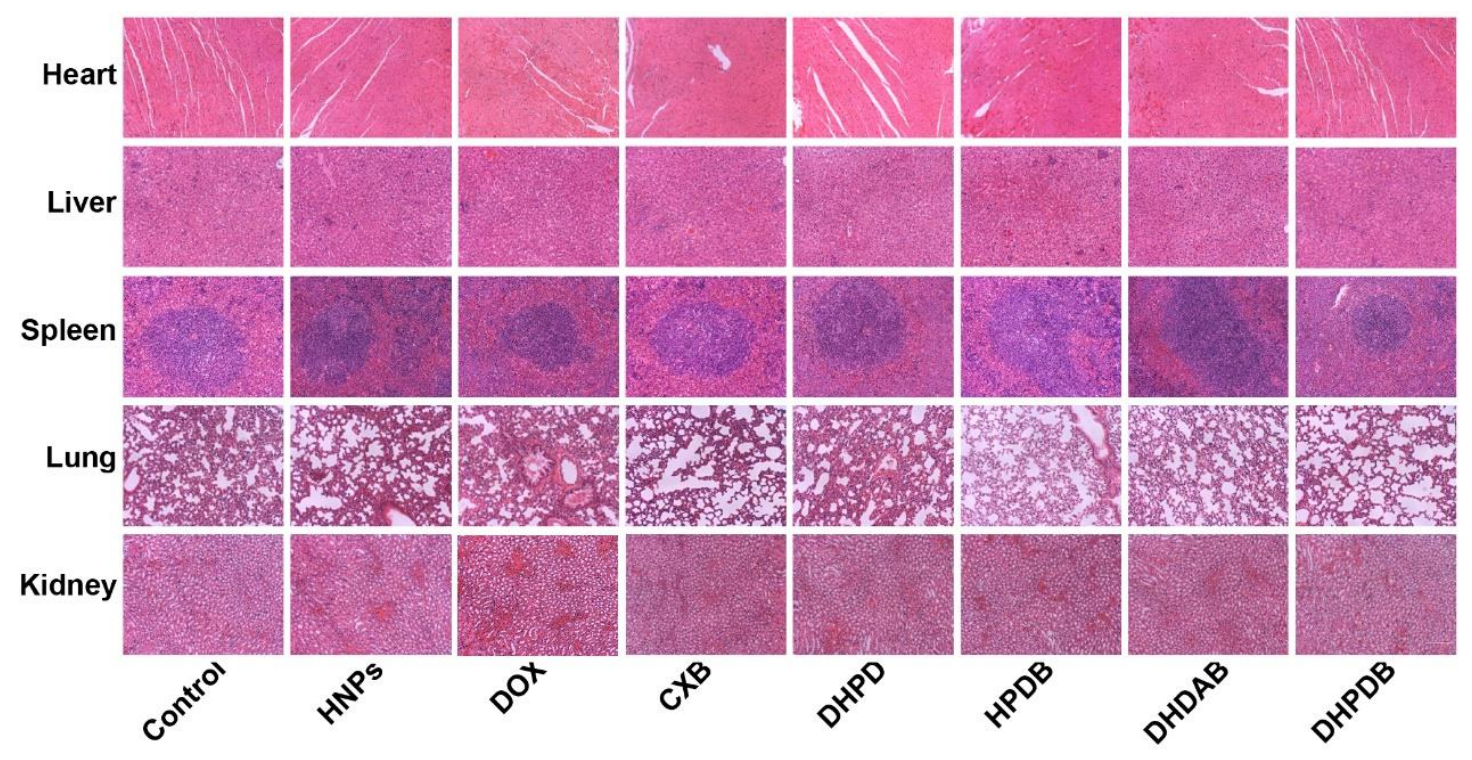

Figure S21. H\&E examination of the heart, liver, spleen, lung, kidney, harvested at the end of antitumor assay (Scale bars $=100 \mu \mathrm{m})$.

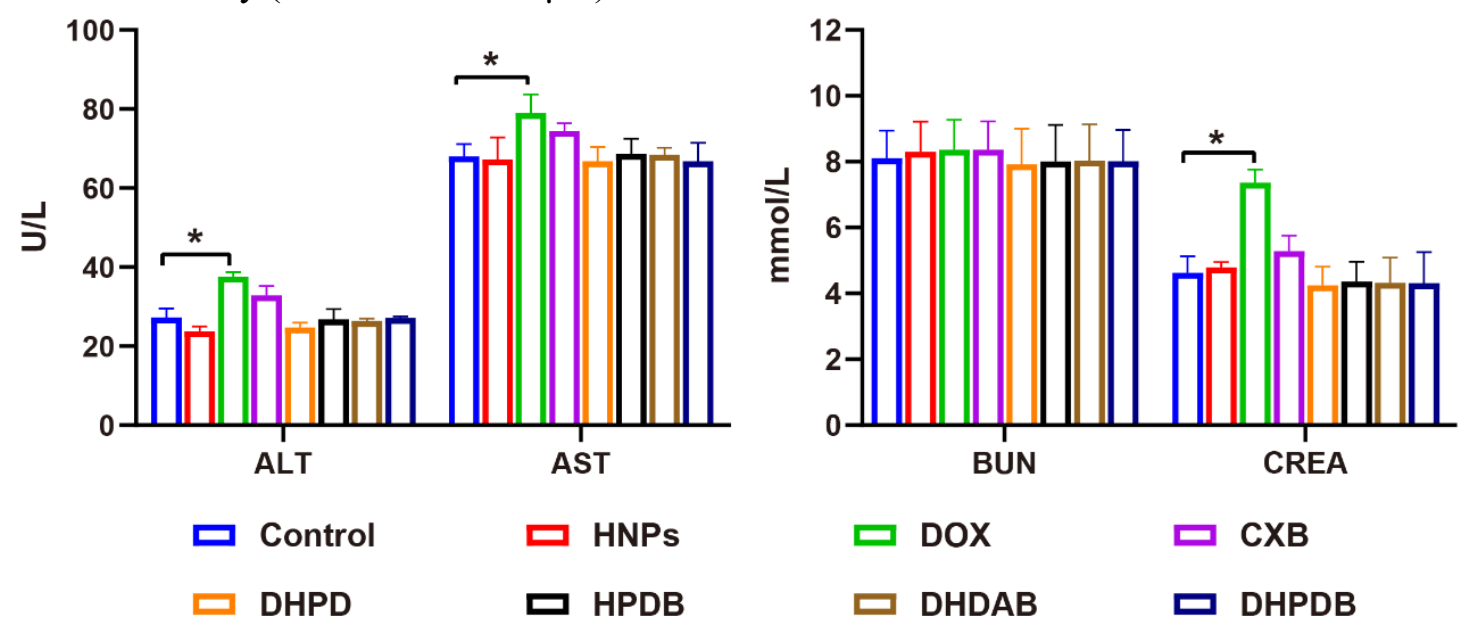

Figure S22. The biochemical analysis of the sera from the mice receiving different treatments ( ${ }^{*} P$ $<0.05)$. 

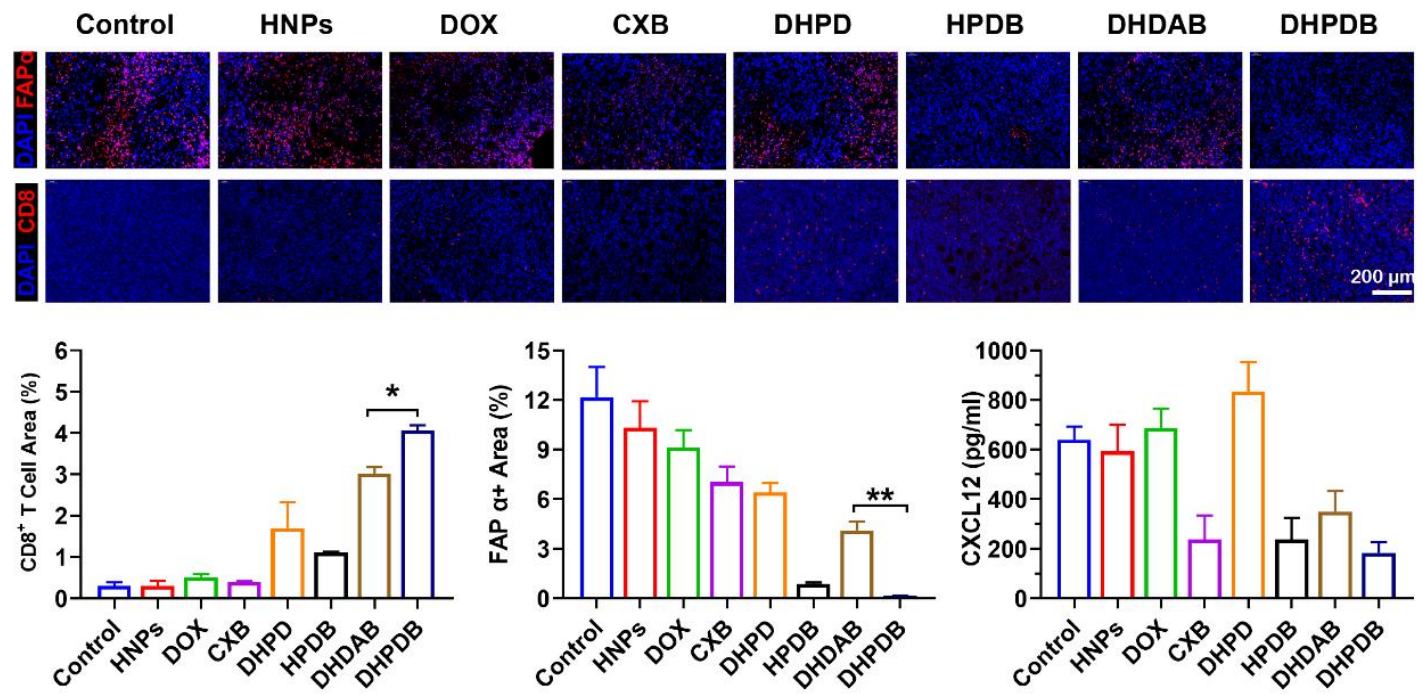

Figure S23. The expression of $\mathrm{CD} 8^{+} \mathrm{T}$ cells, CAF (FAP $\left.\alpha^{+}\right)$and CXCL12 in tumors $\left({ }^{*} P<\right.$ $0.05 ; * * P<0.01)$.

a

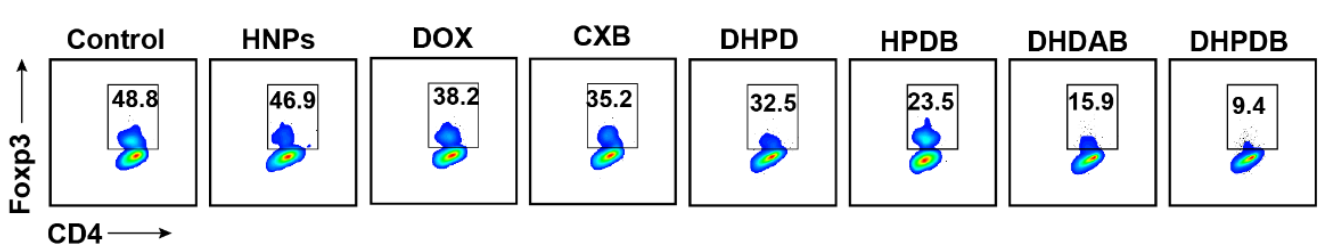

b

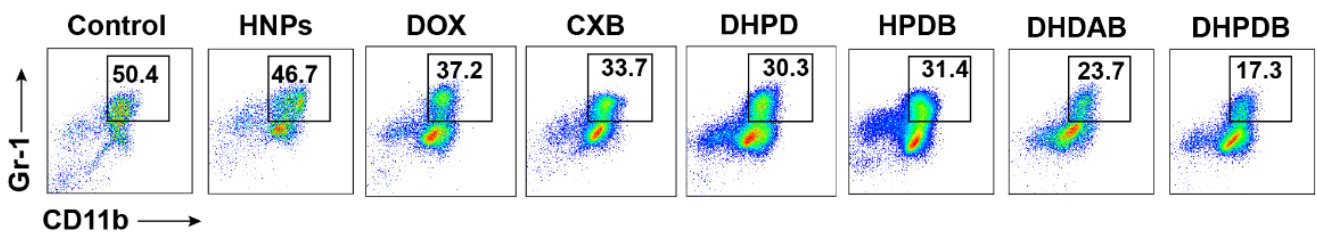

C

Control
$\uparrow$

d
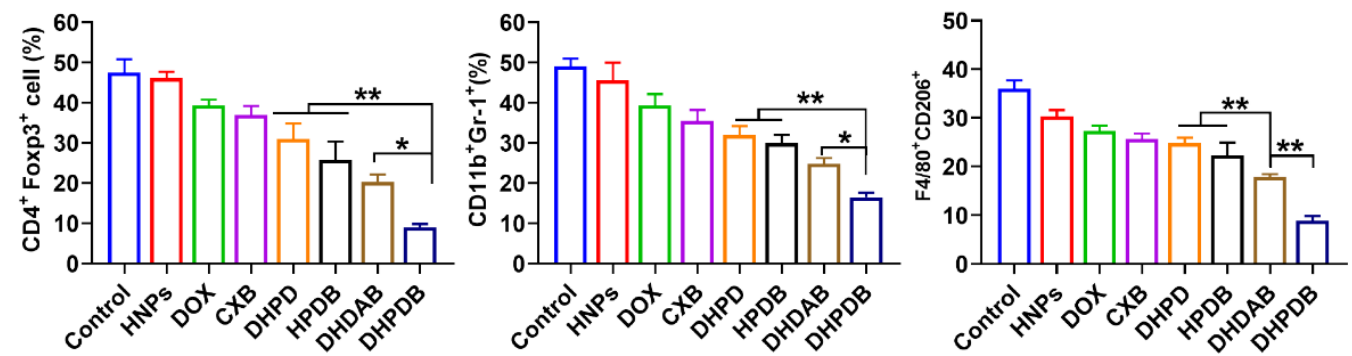

Figure S24. Representative FCM profiles of a) Tregs $\left(\mathrm{CD} 4^{+} \mathrm{Foxp} 3^{+}\right.$cells $)$, b) MDSCs $\left(\mathrm{CD} 11 \mathrm{~b}^{+} \mathrm{Gr}-1^{+}\right.$cells $)$, c) M2-TAMs $\left(\mathrm{CD} 11 \mathrm{~b}^{+} \mathrm{F} 4 / 80^{+} \mathrm{CD} 206^{+}\right.$cells $)$in $4 \mathrm{~T} 1$ tumors. d) Quantitative analysis of Tregs, MDSCs, M2-TAMs in 4T1 tumor site $\left({ }^{*} P<0.05\right.$; $* * P<$ $0.01)$. 

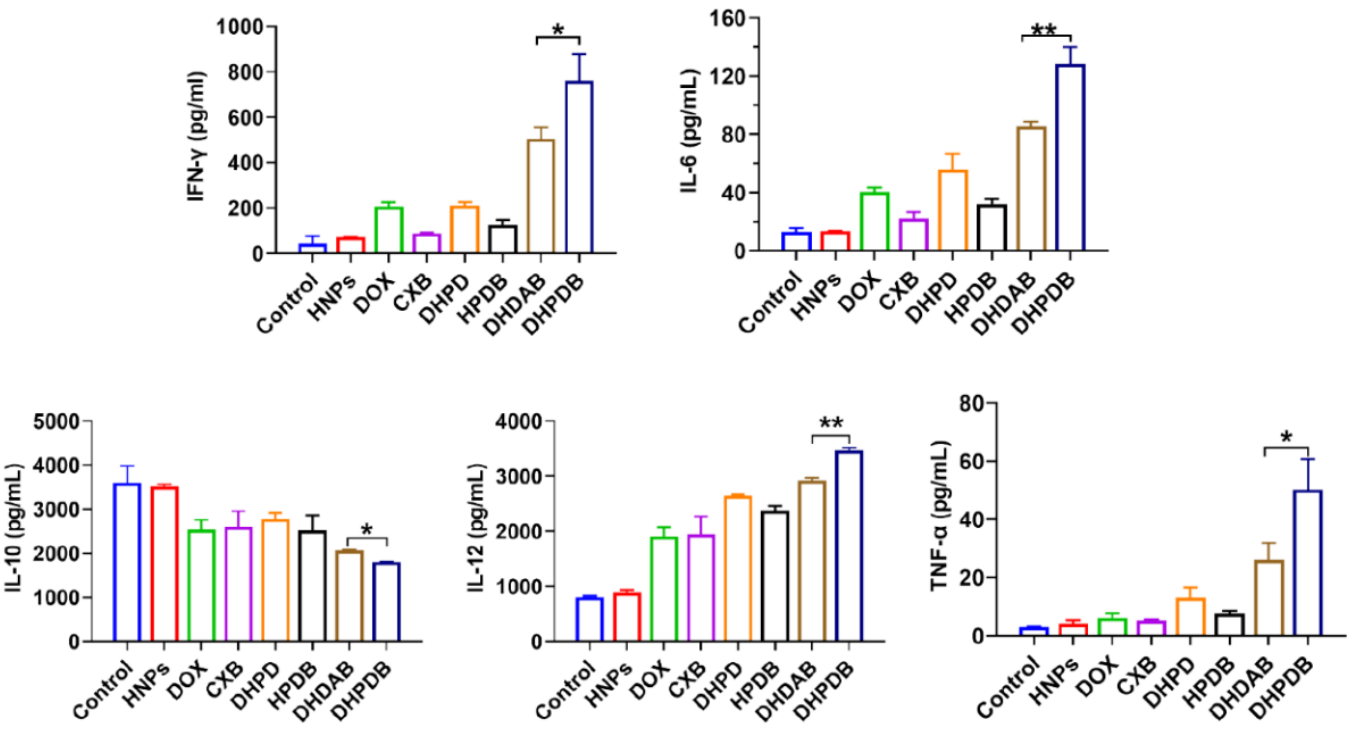

Figure S25. The cytokines IFN- $\gamma$, IL-6, IL-10, IL-12 and TNF- $\alpha$ in serum collected from mice after different treatments $(* P<0.05 ; * * P<0.01)$.

a
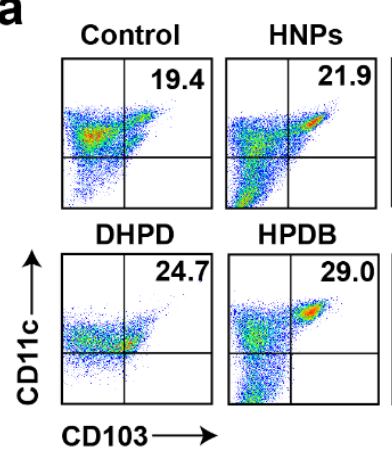

C
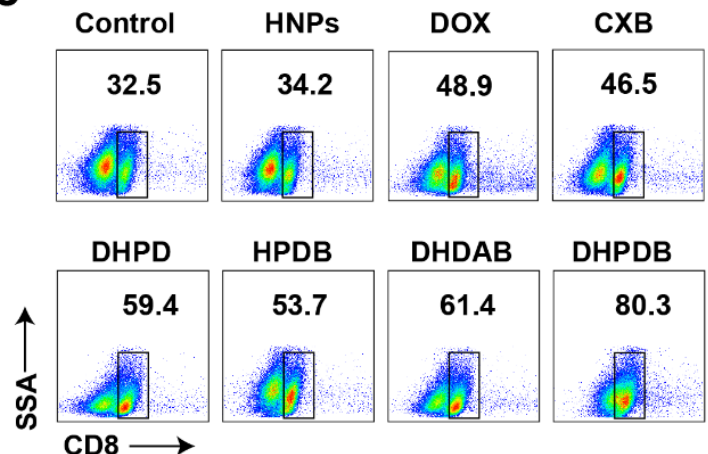

e
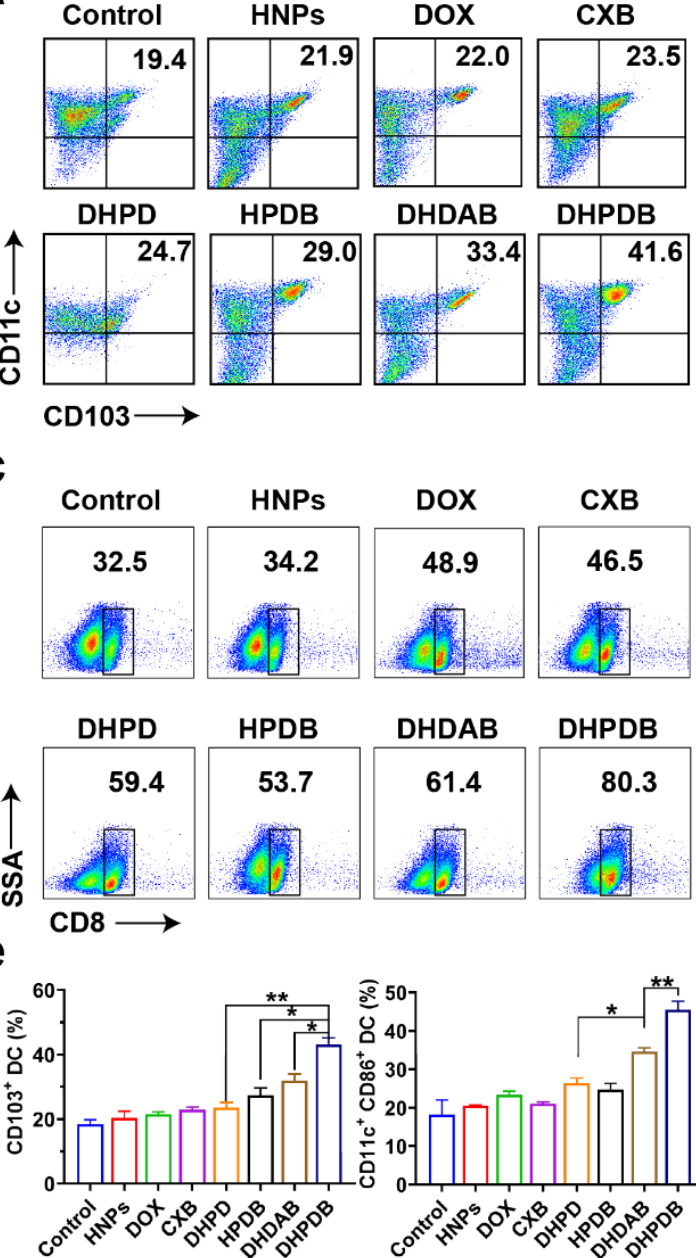

b

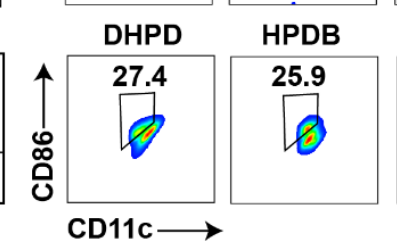

d
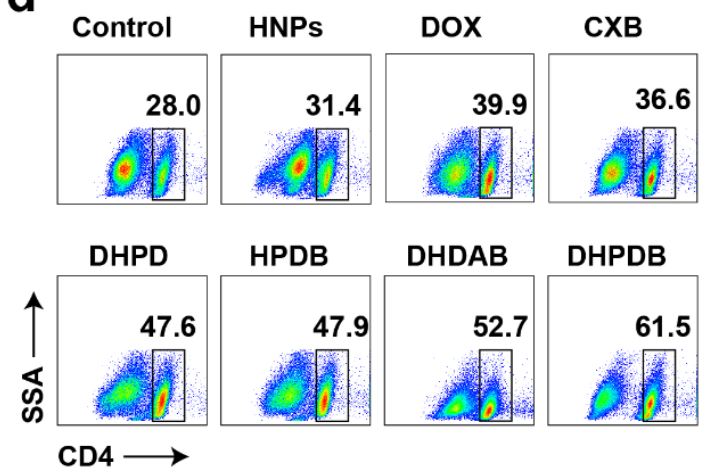

Figure S26. Percentages of a) $\mathrm{CD} 103^{+} \mathrm{DCs}$, b) $\mathrm{CD} 86^{+}$matured DCs, c) $\mathrm{CD} 8^{+} \mathrm{T}$ and d) $\mathrm{CD} 4^{+} \mathrm{T}$ cell infiltrate in dLNs. e) Quantification of DCs, matured DCs, $\mathrm{CD} 8^{+} \mathrm{T}$ and $\mathrm{CD} 4^{+} \mathrm{T}$ cell in 
dLNs $(* P<0.05 ; * * P<0.01)$.

Table S1. The loading efficiency of CXB and DOX in the nanoparticles

\begin{tabular}{|c|c|c|c|c|}
\hline Drugs & \multicolumn{2}{|c|}{ Loading percentage $[\%]$} & \multicolumn{2}{|c|}{ Encapsulation efficiency [\%] } \\
\hline DOX & \multicolumn{2}{|c|}{$8.3 \pm 0.9 \%$} & \multicolumn{2}{|c|}{$80.9 \pm 1.5 \%$} \\
\hline $\mathrm{CXB}$ & \multicolumn{2}{|c|}{$11.4 \pm 1.4 \%$} & \multicolumn{2}{|c|}{$62.9 \pm 2.6 \%$} \\
\hline \multicolumn{5}{|c|}{ Table S2. Pharmacokinetic parameters } \\
\hline Parameter & DOX & DHPDB (DOX) & $\mathrm{CXB}$ & DHPDB (CXB) \\
\hline $\mathrm{t} 1 / 2$ & $0.78 \pm 0.28$ & $4.84 \pm 0.76$ & $1.79 \pm 0.26$ & $5.90 \pm 0.82$ \\
\hline $\mathrm{AUC} \mu \mathrm{g} / \mathrm{ml} * \mathrm{~h}$ & $7.86 \pm 0.72$ & $63.93 \pm 0.26$ & $13.28 \pm 0.16$ & $51.32 \pm 1.37$ \\
\hline
\end{tabular}

